\title{
INPUT, INTERACTION, AND SECOND LANGUAGE PRODUCTION
}

\author{
Susan M. Gass \\ Michigan State University \\ Evangeline Marlos Varonis \\ University of Akron
}

\begin{abstract}
The role of conversational interactions in the development of a second language has been central in the recent second language acquisition literature. While a great deal is now known about the way in which nonnative speakers interact with native speakers and other nonnative speakers, little is known about the lasting effects of these interactions on a nonnative's linguistic development. This paper specifically investigates the relationship among input, interaction, and second language production. Through data from native-nonnative speaker interactions in a direction-giving task, we show that both modified input and interaction affect task performance. However, only interaction has an effect on subsequent task performance.
\end{abstract}

The question of the role of conversational interactions in the development of a second language has been central in the recent second language acquisition literature. While this question has been addressed from a variety of perspectives, it has been difficult to ascertain precisely the role of input and interaction in terms of actual language development. This, in fact, is the thrust of an article by Schachter

Earlier versions of this paper were presented at the Second Language Research Forum, Pittsburgh, 1993, and Association International de Linguistique Appliquee (AlLA), Amsterdam, 1993. We are grateful to Gary Cook for his statistical advice. We are also indebted to India Plough for assistance with transcriptions. The students in English 841 at Michigan State University are appreciated for feedback on the description of the study. Shona Whyte of the SSLA staff made numerous suggestions for improvement on the final manuscript. The SSLA readers provided suggestions, advice, and admonition which we took into consideration as we revised this paper. We are grateful to them for their careful reading of our manuscript. We wish we could say that all errors are theirs, but, alas, we cannot and must confess that any errors are our own. 
(1986) in which she argued for the importance of showing the effect of native speaker input on the language learning process. The purpose of this paper is to see if and in what ways it is possible to determine a direct relationship between input, particularly interactional input, and subsequent language production.

An early view of acquisition held that learners learned grammatical rules and then applied those rules and practiced them within a conversational setting. Thus, classroom drills, classroom interactions, and daily interactions with native speakers were viewed only as a means of reinforcing the grammatical rules acquired by a learner.

In 1975 Wagner-Gough and Hatch suggested a different role for conversation in second language development. They argued that conversational interaction forms the basis for the development of syntax rather than being only a forum for practice of grammatical structures. Syntax, they claimed, develops out of conversation rather than the reverse. Example 1 illustrates the way language development can take place within a conversational setting, as the child learner in this case uses the conversation to further her syntactic development.

1. From Ellis (1985, pp. 79-80)

NS: Do you want to look at the next picture? Yeah?

NNS: Man.

NS: A man. And do you know what this is? A wall.

NNS: A wall.

NS: Like that one there. A wall.

NNS: A wall, a wall.

NS: Yes. Now, can you see what the man is doing?

NNS: A man wall.

NS: He's going into the wall.

Prior to this point in time, there were no examples of two-word utterances in this child's discourse. As can be seen, the conversation itself provides the framework or, as Ellis states, "the breakthrough points" for a two-word utterance to develop. The teacher in this case broke the task into parts and helped with the crucial vocabulary, which finally enabled the child to connect man and wall in her final utterance.

\section{CONVERSATION IN NATIVE-NONNATIVE DISCOURSE}

From this interactional perspective stem a number of studies in which second language conversational interactions and, more broadly, issues of input have become a primary focus in second language research. Long (1980) made an important distinction between modified input, or foreigner talk, and modified interaction, differentiating between the modified talk directed to the learner and the modified structure of the conversation itself. By interactional features, he included such aspects of conversation as comprehension checks, topic shifts, and clarification requests. In his work, Long showed that conversations involving nonnative speakers (NNSs) have more of these kinds of modification than do conversations between two native speakers (NSs). He argued that this is so for two reasons: First, these devices aid in 
avoiding conversational trouble and, second, they serve the function of repairing the discourse when trouble does occur. Varonis and Gass (1985) extended this line of research by operationalizing the concept of negotiation of meaning as a central factor in second language acquisition. An entire volume (Day, 1986) is devoted to precisely the relationship between conversation and acquisition. A number of other studies have considered the effect on nonnative speech of such variables as male/ female differences (Gass \& Varonis, 1986; Pica, Holliday, Lewis, Berducci, \& Newman, 1991), ethnic differences (Scarcella, 1983, 1992), proficiency (Varonis \& Gass, 1985), status and expertise differences (Woken \& Swales, 1989; Zuengler, 1989), and task differences (Duff, 1986; Long, 1980; Pica, 1987; Pica \& Doughty, 1985; Plough \& Gass, 1993; Samuda \& Rounds, 1993). While these studies have significantly contributed to our growing understanding of the factors that influence the nature of speech, they only indirectly touch upon the issue of subsequent L2 production and acquisition. For example, Long (1983) made a deductive argument: Linguistic and/or conversational adjustments lead to better comprehension; comprehension promotes acquisition. Therefore, adjustments facilitate acquisition. An underlying assumption in this body of research is that negotiation increases the possibility that the language used in the negotiation will be of benefit to the learner in the development of the L2 (Ellis, 1991; Gass \& Varonis, 1989; Long, 1992; Pica, 1987).

Despite the promising results of such research, the effect of interaction on acquisition remains controversial. Sato (1986) questioned a direct positive relationship. She examined the English of two Vietnamese boys, finding that neither the NS input to the boys nor the naturalistic interaction between them and their native speaker interlocutor was reflected in increased language proficiency. Her study, focusing on the marking of past time reference, did not suggest that grammatical encoding of such reference increased as a function of proficiency. Instead, the nonnative speakers relied on the situational and/or discourse context to establish a time frame. Since pastness was for the most part recoverable from context, there was an insignificant interactional burden on the part of participants. Furthermore, in the case of past tense marking in English, the feature in question is often not phonologically salient, reducing the learner's opportunities to utilize relevant information. Thus, at least in the case of past tense marking, there is little necessity and little opportunity to obtain or provide linguistic information in the conversation. However, given their relatively rudimentary knowledge of English, one wonders whether the situation might not be different if the learners were at a different stage of development, a stage at which they were "ready" to learn past tense forms (Pienemann, 1992).

Sato's findings have been corroborated by other studies that also focus on NS-NNS naturalistic conversations. Chun, Day, Chenoweth, and Luppescu (1982) reported relatively little explicit feedback in free conversation between native and nonnative speakers and therefore questioned the value of correction as an integral part of successful acquisition. In another study, Day, Chenoweth, Chun, and Luppescu (1984) further questioned the role of error correction in L2 acquisition, noting that out of 1,595 student errors in the corpus, only $119(7.3 \%)$ were singled out for corrective feedback by NS interlocutors.

A follow-up study by Brock, Crookes, Day, and Long (1986) suggested that the 
effect of conversational interactions on acquisition may be influenced in part by task. They investigated a broader range of negative input in native-nonnative free conversations, examining short-term effects of such input on the nonnative's language development. They found surprisingly little change in learner forms, with only 26 out of 152 instances $(17.1 \%)$ in which learners clearly responded by incorporating the native speaker's negative input into their next turn. However, they pointed out anecdotally the possibility of an effect for task: They did observe NNSs incorporating examples of native speaker corrective feedback following errors when communication took place in the context of communication games. In other words, learners' grammars may be quickly destabilized if they give sufficient attention to the area in question, with the assumption being that they would pay more attention in the context of a game as opposed to free conversation. Gass $(1988,1991)$ and Long (1992) have argued for the importance of selective attention in second language development, claiming that it is a prerequisite to grammatical development, a point we return to later. Similarly, Schmidt (1990) argued that conscious awareness is a necessary condition for language development. In addition, it is important to keep in mind that the absence of short-term effects does not exclude the possibility of longterm effects when the learner has had sufficient time to process and incorporate the feedback.

The importance of task is further supported by Crookes and Rulon (1985), who examined native-nonnative dyads, considering the issue of the incorporation of corrective feedback in three situations: One free conversation and two two-way communication tasks. Feedback was defined as the correct usage by a native speaker of a word or construction immediately following a nonnative utterance. They found significantly more feedback in task-related conversation than in free conversation. They suggested that for maximum grammatical destabilization, linguistic material should be slightly unfamiliar to the nonnative speaker, and the structure of the task should require the maximum use of this material by both parties. Pica, Young, and Doughty (1987), in a picture arrangement task in which input to the learner was either premodified or interactionally modified, found that comprehension (as measured by task completion) was superior when the negotiation was allowed as opposed to when it was not. Knox (1992) extended this observation to naturalistic conversation, suggesting that form-focusing and subsequent NNS selfmodification occurs in certain types of constrained settings, such as a structured interview or a service encounter.

The relationship between comprehension and acquisition is further called into question by Doughty (1991). In a study of relativization, she compared three groups of subjects engaged in a computer-assisted language learning project. The groups differed in the format of presentation of the language material. Besides a control group, there were two experimental groups: a meaning-oriented treatment group and a rule-oriented treatment group. As the names suggest, in the latter group, the rule-oriented treatment group, explicit metalinguistic statements about relative clauses were provided, whereas in the meaning-oriented treatment group there were no such explicit statements. The meaning group had higher comprehension scores than the rule-oriented group. However, in terms of pretest/posttest scores 
measuring gains on relative clauses, the two experimental groups improved more or less equally. Thus, at first glance, it appears that there is no direct relationship between comprehension and acquisition. However, a closer examination of the experimental materials brings us back to the question of attention. That is, how can a learner's attention be brought to language forms? It is beyond the scope of this paper to discuss this concept in any detail (cf. Gass, 1988; Schmidt, 1990); however, three aspects are important: form-focused instruction, frequency, and saliency. If we return to Doughty's study, we see that both saliency and redundancy (i.e., frequency) were built into the tasks of the meaning-oriented treatment group. In the experimental material, the meaning-oriented treatment group saw reading passages with certain features, namely, head nouns and relative clause markers, highlighted on the screen. Additionally, the juxtaposed head noun and relative clause marker were capitalized, thereby visually making this part of the reading passage salient to the learner. Thus, Doughty's results (given her particular methodology) suggest that what is important for acquisition is not so much immediate comprehension, but the necessity of drawing learners' attention to particular forms.

Taken as a whole, these studies suggest that NS input is most likely to affect subsequent NNS language production when the interaction is focused and taskoriented.

One difficulty in this area of research is the determination of the learner's knowledge at any particular time. An operating assumption is that we need to assess immediate destabilization of grammatical forms in order to determine the effect of conversational interaction. However, it may be more appropriate (albeit methodologically difficult) to consider longer range effects. Bruton and Samuda (1980) discuss something similar when they refer to "correction by permeation," with correct forms gradually becoming incorporated into the learner's grammar over time.

\section{CONVERSATION IN NONNATIVE-NONNATIVE DISCOURSE}

Up until now we have dealt primarily with research that deals with native-nonnative interactions. There is another area in which nonnative speakers frequently find themselves and that is in conversations with other nonnative speakers. There is evidence that the changes they make as a result of the interaction are in the direction of the target language. Gass and Varonis (1989) presented data from nonnativenonnative interactions that show that a correctly modeled form by a nonnative frequently resulted in changes by the other nonnative in the dyad, although the changes often occurred much later in the discourse. To illustrate such a change as a result of input from another nonnative, we present an example of a grammatical modification in a nonnative's speech that appears to have taken place. In example 2, two nonnatives of different language backgrounds were given the task of going out onto the street with a tape recorder and asking for directions to the train station. These students left the tape recorder on during the entire time they were engaged in this task so that the totality of the conversation between them was also recorded, even when they were not specifically engaged in alternately stopping passersby to ask for directions. 
2. a. Ana: Can you tell me where is the train station?

b. Keiko: Can you tell me where the train station is?

c. Ana: Can you tell me where is the train station?

d. Keiko: Can you tell me where the train station is?

e. Ana: Can you tell me where is the train station?

f. Keiko: Can you tell me where the train station is?

g. Ana: Can you tell me where the train station is?

h. Keiko: Can you tell me where the train station is?

i. Ana: Can you tell me where the train station is?

In understanding the significance of this example, it is important to note that nowhere in the entire conversation between requests for directions did the students discuss the correct grammatical form of English indirect questions. Nonetheless, Ana made an unprompted change in the form of her utterance, from incorrect to correct, while Keiko made no change. This can be seen by Ana's incorrect forms in lines a, c, and e ("Can you tell me where is the train station?") and correct forms in lines g and i ("Can you tell me where the train station is?"), with Keiko using the standard English form all the way through. What is particularly impressive in this example is that the change was made in the direction of the target language and not from a correct target language form to an incorrect one. In a similar vein, in $10 \mathrm{hr}$ of taped conversations between nonnatives, Bruton and Samuda (1980) found only one example of a change from correct to incorrect. In other words, errors of a nonnative speaker peer are generally not incorporated, while one can find numerous examples of modifications in the direction of the correct target language forms. Similarly, Gass and Varonis (1989) found that $89 \%$ of all modifications made as a consequence of an interaction were made in the direction of the target language. This included incorporated changes that occur immediately as well as those that occur after a period of time. Furthermore, we noted additional examples of what we call "incorrections," in which one of the NNSs offered an incorrect repair. In all of these cases, the NNSs did not accept the repair and maintained the form that they had originally used. For instance, in example 3 Hiroko says in his knee and Izumi responds with the incorrect form in him knee. Interestingly, Hiroko maintains the original form in terms of the pronominal case (his knee) but changes the preposition (from in to on), thus clearly recognizing that something was not correct in her original utterance but not incorporating the incorrection. Both finally end up with the correct form, on his knee.

3. From Gass and Varonis $(1989$, p. 81)

Hiroko: A man is uh. drinking c-coffee or tea uh with uh the saucer of the uh uh coffee set is uh in his uh knee

Izumi: In him knee

Hiroko: uh on his knee

Izumi: yeah

Hiroko: on his knee

Izumi: so sorry. on his knee

In example 4, on the other hand, after the incorrection mouth are open, which Midori utters, Yoshi uses an entirely different construction. 
4. From Gass and Varonis (1989, p. 81)

Yoshi: and uhm will she's uhm mouth is open

Midori: mouth are open

Yoshi: She has a rather wide jaw

Thus, although both NS and NNS interlocutors provide corrective feedback in conversation with NNSs, most, but not all of it, is correct, and not all of it is incorporated. Another example of incorporated feedback is offered by Macdonald (1993), who presented evaluations of pronunciation data from learners engaged in interactions. NSs evaluated the pronunciation of NNSs in interactions with other NSs both before and after such interaction. She found that subjects whose interactional strategies indicated an awareness of pronunciation difficulty were more often rated higher after the interaction than those who did not. Her study therefore provides a clear indication of the value of feedback.

The importance of corrective feedback, or negative evidence, has been further argued by White (1987), who suggested that what is necessary is not comprehensible input, but incomprehensible input. It is incomprehensible input that may trigger learners' recognition of the inadequacy of their own rule system. In essence, this is the crux of the interaction argument: Comprehension difficulties, or "instances of non-understanding" (Varonis \& Gass, 1985), are what allow a learner to notice that linguistic modification is necessary.

Through the data we examine in this paper, we attempt to further investigate the relationship among input, interaction, and second language production. The specific hypotheses discussed are the following:

1. Modified input yields better NNS comprehension than unmodified input.

2. Interaction yields better NNS comprehension.

3 . Interaction yields better NS comprehension.

4. Prior interaction yields better L2 production.

5 . Prior input modification yields better $\mathrm{L} 2$ production.

6. Real-world expectations affect comprehension.

\section{METHOD}

\section{Subjects}

Conversations from 16 native-nonnative dyads form the data base for this study. All of the nonnative speakers were enrolled in an intensive language program at a large U.S. university; all of the native speakers were undergraduate students at the same university. All NNSs were at the high intermediate level and were of different L1 backgrounds (Chinese, Turkish, Japanese, German, and Korean). Pairing of nativenonnatives was done by convenience (i.e., according to the times when they were available to participate in the study). 
a. Script

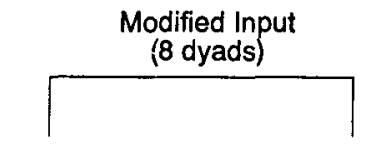

b. Trial 1
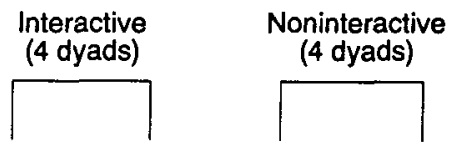

c. Trial 2

Inter. Noninter. Inter. Noninter. (2 dyads) (2 dyads) (2 dyads) (2 dyads) (2 dyads) (2 dyads) (2 dyads) (2 dyads)

Unmodified Input

(8 dyads)

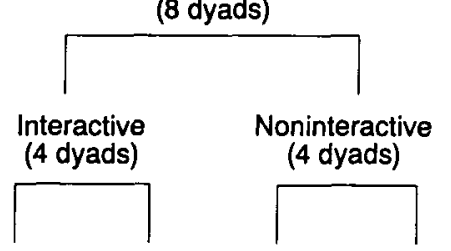

Inter. Noninter. Inter. Noninter.

Figure 1. Diagram of experimental design.

\section{Procedure}

Each member of the dyad performed a task in which he or she had to describe to a partner where to place objects on a board. The boards were depictions of an outdoor scene, in the first trial a beach scene and in the second a farm scene. The objects included human figures, animals, and inanimate objects. The describers, who were visually separated from their partners, had a board on which 20 objects were glued. The partner had an identical board with the identical 20 objects placed to one side. The task, then, was to describe to one's partner where to place these objects (Trial 1). In every case the native speaker first read from a script provided by the researchers. After this description, a second board, with the identical 20 objects, was given to the nonnative to describe (Trial 2). Each trial took approximately $20 \mathrm{~min}$, with roughly 5 min separating the two trials.

\section{Design}

Prior to the start of data collection, a native-native pair and a native-nonnative pair performed the first task described above, using the board for Trial 1. In neither case was interaction allowed. None of these four individuals participated in the actual study. The descriptions were recorded and then transcribed. The transcripts of both pairs were used as the script for Trial 1. The script taken from the description of one native speaker to the other native speaker was designated unmodified input; the script taken from the description of the native speaker to the nonnative speaker was designated modified input.

The 16 NS-NNS dyads in the study were divided into two subgroups: a modified input group and an unmodified input group, illustrated in Figure 1, part a.

The groups were differentiated by the kind of input that the native speaker (the NS member of one of the 16 NS-NNS dyads) gave to the nonnative speaker. In both groups the NS followed one of the two scripts, transcribed from the data gathered prior to the study.

Each of these two subgroups was further subdivided into two more subgroups according to whether or not normal interaction (including requests for repetition, clarification, comprehension checks, etc.) was allowed during the first description 
Table 1. Number wrong on first trial: Nonnative speaker placement of objects based on native speaker directions

\begin{tabular}{lccc}
\hline & \multicolumn{3}{c}{ Input Type } \\
\cline { 2 - 4 } & $\begin{array}{c}\text { Modified } \\
(N=160)\end{array}$ & $\begin{array}{c}\text { Unmodified } \\
(N=160)\end{array}$ & $\begin{array}{c}\text { Total } \\
(N=320)\end{array}$ \\
\hline Noninteractive $(k=160)$ & 36 & 47 & 83 \\
Interactive $(k=160)$ & 24 & 37 & 61 \\
Total $(k=320)$ & 60 & 84 & 144 \\
\hline
\end{tabular}

Note: Total opportunities for error $=320$ (16 subjects $\times 20$ figures $)$ or 80 in each of four cells.

(see Figure 1, part b). Finally, there was one additional subdivision, illustrated in part c of Figure 1, depending on whether interaction was allowed during the second description (i.e., when the nonnative speaker was describing). The nonnative description was not scripted, as it was our intent to see which of the input and interaction conditions led to more successful descriptions by the nonnative.

Our dependent variable was comprehension on the part of the NNS (Trial 1) and the NS (Trial 2), as measured by the degree to which subjects were able to understand instructions and hence accurately place objects on the board. ${ }^{1}$

\section{RESULTS}

The results are presented in terms of number wrong, determined by the accurate versus inaccurate placement of the objects on the board. On the first trial, we take this to be a measure of the NNS's ability to comprehend the instructions. On the second trial, we take this to be the measure of the NNS's success at using the language to give appropriate instructions.

\section{Nonnative Speaker Performance Based on Native Speaker Descriptions}

We first consider the results of Trial 1 in terms of both of our experimental conditions: (a) modified versus unmodified input (Hypothesis 1) and (b) interaction versus noninteraction (Hypothesis 2). As can be seen in Table 1, nonnative speakers made fewer errors $(60 / 160)$ when they received modified input than when they received unmodified input $(84 / 160)$ from the native speaker direction-giver. This difference was significant (Mann-Whitney $U, p=.0087$ ). ${ }^{2}$ Similarly, nonnative speakers made fewer errors $(61 / 160)$ when interaction was allowed than when it was not allowed $(83 / 160)$. Here, too, the difference was significant $(p=.0209)$. Thus, both the condition of modified input and the opportunity for interaction resulted in significantly fewer errors, confirming our first two hypotheses. In fact, the most successful condition (24/80 possible errors, or $30 \%$ ) was that in which NNSs received modified 
Table 2. Number wrong on second trial:

Native speaker placement of objects based on nonnative speaker directions

\begin{tabular}{cc}
\hline Interactive Group & Noninteractive Group \\
\hline 26 & 30 \\
\hline
\end{tabular}

Note: Mann-Whitney $U, p=.6744$, n.s.

Table 3. Number wrong on second trial as a function of interaction on first trial

\begin{tabular}{cc}
\hline First Trial Interactive & First Trial Noninteractive \\
\hline 8 & 48 \\
\hline
\end{tabular}

Note: Mann-Whitney $U, p=.0039$.

input and had the opportunity to interact with the direction-giver, whereas the least successful condition ( $47 / 80$ possible errors, or $59 \%$ ) was that in which the input was unmodified and interaction was not allowed (a combination of Hypotheses 1 and 2).

\section{Native Speaker Performance Based on Nonnative Speaker Descriptions}

We next look at the results of the second trial, in which the NNSs switched roles with the NS interlocutors and gave rather than received directions. We first examine the effect of interaction on the second trial on object placement (Hypothesis 3 ). There were 26 out of 160 possible errors when interaction was allowed, as opposed to 30 out of 160 possible errors when interaction was not allowed (see Table 2) (MannWhitney $U, p=.6744$, n.s.). Thus, unlike the results in the first trial, on this trial there is no clear indication that interaction had an effect on the outcome, disconfirming Hypothesis 3 . The opportunity for interaction in the discourse did not affect the NNSs' ability to provide more accurate and comprehensible instructions to their NS partners.

\section{Effects of Interaction}

Our main research agenda was to determine whether there are linguistic effects (evident in the NNS's productive trial) as a result of prior interaction. In Table 3 we isolate the effect that interaction on the first trial has on success on the second trial (Hypothesis 4). Here, the results are striking. Clearly, the NNSs who had the opportunity to interact on the first trial, when they were receiving directions, were better able to give directions on the second trial, as indicated by the number of times the NSs receiving directions incorrectly placed objects on the board (Mann-Whitney $U, p$ $=.0039$ ). When the NNS had had the opportunity to interact on the first trial, the NS made only 8 out of a possible 160 errors $(5 \%)$ on the second trial; in contrast, when 
Table 4. Number wrong on second trial as a function of modification on first trial

\begin{tabular}{cc}
\hline First Trial Modified & First Trial Unmodified \\
\hline 41 & 15 \\
\hline
\end{tabular}

Note: Mann-Whitney $U, p=.0587$ (approaching significance).

the NNS had not had the opportunity to interact on the first trial, the NSs made 48 errors $(30 \%)$ on the second trial. Thus, the NNSs performed better or gave more accurate descriptions when the first trial had allowed them to interact with the NSs who were describing.

A second variable that could influence performance on the second trial was the presence of modified or unmodified input on the first trial (Hypothesis 5). Would NNSs who had received modified input on the first trial, resulting in better performance on Trial 1, be better prepared to give directions in Trial 2? This turned out not to be the case. There were more errors on the second trial in those conditions in which there had been modified input on the first trial $(41 / 160[26 \%]$ vs. $15 / 160[9 \%])$ (Mann-Whitney $U, p=.0587$ [approaching significance]). These findings are shown in Table 4. This result is particularly interesting in light of the fact that modified input resulted in greater success on the first trial, when the NNS was following rather than giving directions. Thus, Hypothesis 5 is disconfirmed, at a level closely approaching significance. It appears that receiving modified input may help a nonnative speaker's comprehension in the short run, but may be a deterrent in subsequent language production.

\section{Real-World Expectations}

We also considered whether or not accuracy was at all dependent on expectations subjects might have about where the objects should go, given real-world knowledge (Hypothesis 6). This is one way of measuring whether interlocutors rely more on context than on grammar as an aid in comprehending speech. We had designed the board so that half of the objects were placed appropriately, as, for example, a frog in a pond, or a little girl with a watering can watering flowers. The other half were placed in an unusual manner, as, for example, an automobile in a cloud, or a cat sleeping on a lake. When we looked at the number wrong in relation to this dimension, we found that whether or not an object was in an expected place had little effect on a subject's ability to describe or place the object. On Trial 1 there were 68 errors when the objects were in an expected location and 64 when they were in an unexpected location. ${ }^{3}$ Similar results were noted on Trial 2: When the objects were in an expected location, there were 29 errors as opposed to 24 when they were in an unexpected location (see Table 5). Thus, at least in this controlled study, real-world expectations are not an important factor in comprehension. ${ }^{4}$ 
Table 5. Number wrong as a function of real-world expectations

\begin{tabular}{lcc}
\hline & Usual & Unusual \\
\hline First trial & 68 & 64 \\
Second trial & 29 & 24 \\
\hline
\end{tabular}

\section{Summary of Results}

In sum, the results indicate that both modified input and interaction affect immediate task performance. When the NS is the speaker, both of these conditions lead to greater NNS comprehension, as measured by task performance. Furthermore, the opportunity to interact when receiving directions in turn enables the NNS to provide better directions on a subsequent trial. This is not the case, however, when the initial directions include modified input. The NNS who receives modified input is better able to understand directions but subsequently less able to offer clear directions than the NNS who receives unmodified input. In terms of our original six hypotheses, 1, 2 , and 4 were confirmed and 3,5 , and 6 were disconfirmed.

\section{DISCUSSION}

\section{The Effect of Modified Versus Unmodified Input}

In discussing these results, the first question we seek to address relates to the input conditions. Consistent with previous research (cf. Parker \& Chaudron, 1987, for a review of this literature ${ }^{5}$ ), our results show that modification significantly and positively affects comprehension. The NNSs were better able to comprehend when listening to a modified script as opposed to an unmodified script regardless of whether or not interaction was allowed.

However, the modified condition had a negative effect on the subsequent trial (when NNSs gave directions), suggesting that the linguistic information contained in the unmodified version was better suited for later language production. In 5 are examples from the modified condition and in 6 are examples from the unmodified condition.

5. Modified condition

a. On the other two stones of that path, put the dog. There's a little brown dog. So he's on the stones close to the stairs.

b. At the top of those stairs, the three brown stairs, going up to the house, at the top of those stairs, put the yellow cat.

c. Above the sun, place the squirrel. He's right on top of the sun.

6. Unmodified condition

a. Also along that path is the dog. So the dog is on the first two stones of that path. In other words, he's right next to the stairs of the house. 
b. The cat is at the top of the stairs. And she's against the house, against the far right side of the front part of the house.

c. Now we're going to go to the sun, and the squirrel is right on the sun.

In considering what differentiated these two conditions, we note that in the unmodified utterances, the object to be placed tends to be overtly stated as both the topic and grammatical subject at the beginning of the discourse, while in modified utterances, the object to be placed appears as the grammatical object of the sentence following phrases that locate that object in space. For example, in the modified condition, the cat (example b) is not invoked until the end of the utterance (in the position of new information); until this time, the hearer's linguistic attention may be "on hold." In contrast, in the unmodified condition, the object to be placed, the cat, appears as both topic and subject at the beginning of the utterance. This reduces the burden on learners since once they identify the object to be placed, all of their attention can be directed toward the descriptions involved in actual placement.

The unmodified condition also contained greater elaboration than the modified condition. The unmodified script evidenced more types of expressions than the modified script, which is characterized by a more limited vocabulary. This is seen in the unmodified directions, which include such prepositions as along, next to, and against, which are lacking in modified directions. In addition, the unmodified transcript, unlike the modified transcript, evidences the use of cohesive devices such as also, so, in other words, and now. Our findings are consistent with work by Parker and Chaudron (1987), who, in a review of the literature on modification, note that elaborations are more likely to increase comprehension (cf. also Long \& Ross, 1992 , for the relationship between retention and elaboration, and Ross, Long \& Yano, 1992, for a discussion of the relationship between text type and comprehension). In general, it appears that the unmodified condition, with its greater elaboration, linguistic redundancy, and more explicit topic nominations allows for comprehended input (Gass, 1988). It is comprehended input that is necessary for acquisition (or, at least, later language production), because such input affords the learner the opportunity for analysis, a prerequisite for new or restructured grammatical knowledge (cf. Sharwood Smith's 1991 notion of enhanced input).

\section{The Effect of Interaction}

The second issue we address is the effect of interaction on subsequent performance. We had hypothesized (Hypothesis 4) that the second trial would yield more accurate results when the first trial was interactive. In fact, as we have shown, this was the case. However, we had thought that the major linguistic area where this would surface would be in the area of the lexicon. An interactive situation is one in which unknown lexical items could be clarified; learners could use the first trial to gain information about unknown vocabulary and then use these words to become more precise in their descriptions. This turned out not to be the case, as we were unable to find any examples where unknown lexical items (as evidenced by the need to 
negotiate their meaning on the first trial) were used correctly on the second trial (see also Loschky, 1994).

What learners did seem to take from the first trial were various descriptive devices that NSs had used to explain unknown lexical items. An example is given in 7 below.

\section{First trial}

Jane: All right now, above the sun place the squirrel. He's right on top of the sun.

Hiroshi: What is ... the word?

Jane: $O K$. The sun.

Hiroshi: Yeah, sun, but ...

Jane: Do you know what the sun is?

Hiroshi: Yeah, of course. Wh-what's the

Jane: Squirrel. Do you know what a squirrel is?

Hiroshi: No.

Jane: $O K$. You've seen them running around on campus. They're little furry animals. They're short and brown and they eat nuts like crazy.

Second trial

Hiroshi: The second thing will be ... put here. This place is ... small animal which eat nuts.

Jane: Oh, squirrel?

Hiroshi: Yeah (laughter).

In the first trial Jane is trying to describe to Hiroshi where to place the squirrel, a word that Hiroshi did not know. Jane's description includes a physical description of the animal as well as a description of what it eats. In the second trial Hiroshi does not use the specific lexical item, squirrel, using instead the same descriptive device Jane had offered on the previous trial. It is likely that the NNS's use of eat nuts to describe what a squirrel does comes as a result of input during the first trial. ${ }^{6}$

Turning to data from nonnative speakers whose first trial was noninteractive, a slightly different situation obtains. In the second trial they also took linguistic information provided for them in the first trial but did not necessarily use it in an appropriate manner. For example, in the native speaker script there were numerous examples of phrases such as "you will find" and "you will see" (examples are given in 8a). Additionally, there are statements and/or questions that do not necessitate the future marker (as in example $8 \mathrm{~b}$ ).

8. Instructions from NSs to NNSs

a. You'll find the beach ball is to the left of the red chair.

You'll see there's a green light above...

b. You see the little point that comes up from the apex of the triangle.

c. You see where the two sides intersect?

In the native speaker's description, the use or lack of use of the future marker depended on whether the speaker was giving instructions (in which case the future was used) or attempting to determine whether the interlocutor's attention was fo- 
cused on the relevant object (a form of questioning). In 9a and 9b are examples from a nonnative speaker's description in which the future marker was used; but nonnative speakers also use the verb form without the future marker $(9 \mathrm{c})$ for instruction giving, a form-function relationship not found in native speaker usage.

9. Instructions from NNSs to NSs (noninteractive first trial)

a. Then, you will see a ... is a wooden fan.

b. There ... there's a uh the far, far, right, farrest right farrest right you will see the tree.

c. And uh then you see the girl with uh blue ... skirt.

In descriptions by native speakers there was frequent use of the word put, or place, but never in conjunction with will, unless there had been prior "scene-setting" information. In 10 is an example of an extension of a form to an environment not present in the native speaker discourse. This nonnative speaker appears to adopt the native speaker mode for instruction giving but generalizes to inappropriate environments. Examples such as 10 in which the description begins abruptly with you will put the cat did not occur in the data from nonnative speakers in which the first trial was interactive. In other words, NSs did not use this device as a way of introducing new information, as this NNS did.

10. You will put the cat uh under that two stone...

Thus, it appears that the opportunity for prior interaction allows the NNS to spend more time considering the linguistic input, even if the interaction is task oriented and not language oriented. This opportunity for latent linguistic processing when the learner's attention is focused on another task may have an important effect on the reorganization of linguistic knowledge and subsequent language production.

\section{CONCLUSIONS}

Arguments concerning the importance of interaction and/or modified input for second language acquisition have been primarily indirect. For example, Long (1985) makes a three-step argument for the existence of a causal relationship. First, one shows that linguistic/conversational adjustments promote comprehension of the input. Second, one argues that comprehension and acquisition are directly related. As comprehension increases, so does acquisition. Third, one must deduce that adjustments promote acquisition.

A second type of argument has been made by Scarcella and Higa (1981) and Varonis and Gass (1985). This argument has to do with the amount of work that participants put into the conversation and how much effort they make to gain comprehensible input. However, this cannot be sufficient, for if it were only a matter of negotiation, then the most successful cases would be those in which there was interaction. In the current study, however, only the opportunity for interaction on the first trial yielded significant results. There were fewer errors in placement on the 
first and second trials when the first trial had been interactive, while interaction on the second trial did not have a significant effect. Thus, the greatest effect on the successful completion of the task was the NNS's opportunity for preceding interaction.

It appears, then, that the results of interaction are not necessarily immediate. That is, they may not affect the conversation in which the interaction takes place, as much as they do subsequent conversations.

How can we account for these results? One possible explanation is that the first trial, when interactive, provided a longer amount of time for using language. This would suggest that time on task is the crucial variable. While time on task may be a partial contributor to an explanation, it is not a sufficient one, because there appear to be other issues involved as well. We turn our attention to language-related issues and in particular to native speaker- and nonnative speaker-initiated negotiations and argue that this part of the discourse focuses a learner's attention on linguistic form, on ways of creating discourse, and, in particular, on ways of describing objects.

In 11 are instances of native speaker-initiated input clarifications (i.e., feedback) and in 12 instances of nonnative speaker-initiated negotiated forms.

11. Focus on form-native speaker initiated

a. Correction

NNS: Is he in the ... pool? Is he in the sea?

$\rightarrow \quad$ NS: Yes. In the ocean. He has a hoe in his hand.

b. Unsolicited explanation

NS: OK. Remember we weren't sure which flower it was? It's the one that has a stem. Do you know what a stem...?

NNS: A stem.

$\rightarrow \quad$ NS: It's a line.

NNS: Oh, I see. I see.

NS: OK. Did you pick the right flower?

NNS: Uh.

NS: It's the one y'know y', the flower and you have the stem.

c. Comprehension check

NS: Now, let's go to the dock.

NNS: Dock.

NS: We're moving to the left of the board, but we're still in the water. Above the water is a brown dock. Now ...

NNS: Dog I I have to move this dog.

NS: OK, that's a dog. This is a dock.

NNS: Duck.

$\rightarrow \quad$ NS: Dock, do you know what a dock is?

NNS: Yeah.

NS: OK.

NNS: (softly) What's the dock?

12. NNS-initiated negotiations

a. Targeted question

NS: You will see a path that has four stones on it next to the house.

$\rightarrow \quad$ NNS: Pat?

NS: A path.

NNS: OK. Uh huh. 
b. Request for repetition/definition

NS: Now underneath the second tree, follow the tree all the way down in the brown part, in the dirt, you'll put the saw ... in the dirt you'll put the saw.

$\rightarrow$ NNS: What's saw? Could you repeat it please?

It is clear that negotiations are what differentiate the interactive from the noninteractive conditions. We suggest that they crucially focus the learner's attention on the parts of the discourse that are problematic, either from a productive or a receptive point of view. Attention, in turn, is what allows learners to notice a gap between what they produce/know and what is produced by speakers of the L2. The perception of a gap or mismatch may lead to grammar restructuring.

The importance ascribed to attention can also be seen in the general literature of education. Osborne and Wittrock (1983) stated,

The pathway to the construction of meaning from an experience does not begin with that experience. Rather, it begins with selective attention [italics added] of that experience where selective attention is influenced by a variety of aspects of long-term memory and cognitive processes. (p. 494)

The concept of attention is not new in the second language acquisition literature. Hakuta (1976) noted that overtly marked forms in a language penetrate a learner's attention and are learned earlier than forms without overt marking. More recently, Nagle and Sanders (1986) discussed the essential role of attending in the process of comprehending. In their terms, "attending involves the application of mental energy to processing tasks and may range from focusing on specific features of input to controlled processing for retrieval" (p. 17). There are other similar proposals: Bardovi-Harlig (1987) proposed the concept of "salience" to account for acquisition facts of second language learners, facts that are difficult to account for in any existing models of second language acquisition, and Schmidt (1990) made the strong claim that learning cannot take place without conscious awareness. Similarly, Long (1992) has argued for the importance of attention-focusing devices in second language learning. (For a recent review of the literature on attention as it relates to second language acquisition, see Tomlin \& Villa, 1994).

What we claim is that interactional input provides a forum for learners to readily detect a discrepancy between their learner language and the target language and that the awareness of the mismatch serves the function of triggering a modification of existing second language knowledge, the results of which may show up at some later point in time. Destabilization, then, is crucial if learning is to progress to higher levels. The data presented here show that this interactive effect is not just an immediate one (cf. also Gass \& Varonis, 1989).

In sum, we have attempted to establish a methodology for directly investigating the relationship between interactively modified input and second language production. We have demonstrated the impact of interaction on later language use. We utter a cautionary note in that we are only in a position to talk about later language 
use; we are not yet in a position to talk about the effect of interaction on actual incorporation of forms. What this study shows is the potential effect of interaction. The notion of retention, a concept strongly allied to memory, must be addressed in future research. We have argued that interaction serves to focus learners' attention on form in instances where there is some perceived difficulty in communicating, raising to a level of awareness that area of a learner's grammar that deviates (either productively or receptively) from native speaker usage. Finally, we have argued that this raising to awareness is a prerequisite for the restructuring of a learner's linguistic knowledge.

\section{(Received 9 December 1993)}

\section{NOTES}

1. One could argue that this measure provides only an indirect measure of actual comprehension and production. This is clearly the case, but it is to be noted that we were not necessarily interested in a description of the two different transcripts as the literature is replete with descriptions of foreigner talk. What we were interested in was a global assessment of comprehension on the part of the NNS (Trial 1) and of the NS (Trial 2)-This latter we assumed to be a function of the NNS's facility with the L2. Since 16 different NSs were involved in the study, it is unlikely that the differences found were artifacts of individual differences.

2. A Mann-Whitney test is similar to a $t$ test, testing medians rather than means. It is, therefore, a more conservative measure. It is often used when the $n$ size is small, since it does not assume a normal distribution.

3. These results do not include all instances of incorrect placement since, for the first two dyads tested, only the number wrong was recorded rather than a listing of the actual objects that had been incorrectly placed.

4. This may in part be due to the nature of the experimental paradigm. Since participants were in a situation of "play" (i.e., placing objects on a board), expectations of reality were suspended. In other words, in this particular context, "anything goes."

5 . The literature on the effect of linguistic adjustments is not completely clear-cut. For example, elaborations appear to better facilitate comprehension than do linguistic adjustments, although some evidence indicates that linguistic adjustments are beneficial.

6. An interesting possibility suggested by a reviewer is that Hiroshi is involved in "transitional incorporation." That is, the first trial led Hiroshi to "notice the gap" (i.e., his lack of lexical knowledge), and he is now using a descriptive device as a strategy for compensating for his lack of knowledge.

\section{REFERENCES}

Bardovi-Harlig, K. (1987). Markedness and salience in second-language acquisition. Language Learning, 37, $385-407$.

Brock, C., Crookes, G., Day, R., \& Long, M. (1986). The differential effects of corrective feedback in nativespeaker conversation. In R. Day (Ed.), Talking to learn: Conversation in second language acquisition (pp. 229-236). Cambridge, MA: Newbury House.

Bruton, A., \& Samuda, V. (1980). Learner and teacher roles in the treatment of error in group work. RELC Journal, $11,49-63$.

Chun, A., Day, R., Chenoweth, A., \& Luppescu, S. (1982). Errors, interaction, and correction: A study of native-nonnative conversations. TESOL Quarterly, 16, 537-547.

Crookes, G., \& Rulon, K. (1985). Incorporation of corrective feedback in native speaker/non-native speaker conversation. TESOL Quarterly, 19,607.

Day, R. (Ed.). (1986). Talking to learn: Conversation in second language acquisition. Cambridge, MA: Newbury House.

Day, R., Chenoweth, A., Chun, A., \& Luppescu, S. (1984). Corrective feedback in native-nonnative discourse. Language Learning, 34, 19-45.

Doughty, C. (1991). Second language instruction does make a difference: Evidence from an empirical study of SL relativization. Studies in Second Language Acquisition, 13, 431-469. 
Duff, P. (1986). Another look at interlanguage talk: Taking task to task. In R. Day (Ed.), Talking to learn: Conversation in second language acquisition (pp. 147-181). Cambridge, MA: Newbury House.

Ellis, R. (1985). Understanding second language acquisition. Oxford: Oxford University Press.

Ellis, R. (1991, April). The interactional hypothesis: A critical examination. Paper presented at the RELC Conference, Singapore.

Gass, S. (1988). Integrating research areas: A framework for second language studies. Applied Linguistics, 9 , 198-217.

Gass, S. (1991, December). ELT methodology from a learning perspective. Paper presented at Second Chulalonkorn University Conference on Language Teaching, Bangkok, Thailand.

Cass, S., \& Varonis, E. (1986). Sex differences in NNS/NNS interactions. In R. Day (Ed.), Talking to learn: Conversation in second language acquisition (pp. 327-351). Cambridge, MA: Newbury House.

Gass, S., \& Varonis, E. (1989). Incorporated repairs in nonnative discourse. In M. Eisenstein (Ed.), The dynamic interlanguage: Empirical studies in second language variation (pp. 71-86). New York: Plenum Press.

Hakuta, K. (1976). Becoming bilingual: A case study of a Japanese child learning English. Language Learning, $26,321-351$.

Knox, L. (1992, April). Cooperative fellow speakers and the enrichment of input: An application of relevance theory. Paper delivered at the Second Language Research Forum 1992, Michigan State University, East Lansing.

Long, M. (1980). Input, interaction and second language acquisition. Unpublished doctoral dissertation, University of California, Los Angeles.

Long, M. (1983). Linguistic and conversational adjustments to non-native speakers. Studies in Second Language Acquisition, 5, 177-193.

Long, M. (1985). Input and second language acquisition theory. In S. Gass \& C. Madden (Eds.), Input in second language acquisition (pp. 377-393). Rowley, MA: Newbury House.

Long, M. (1992, March). Input, focus on form, and second language acquisition. Paper presented at the American Association of Applied Linguistics annual meeting, Seattle, WA.

Long, M., \& Ross, S. (1992). Modifications that preserve language and meaning. In M. Tickoo (Ed.), Simplification. Singapore: Regional Language Center.

Loschky, L. (1994). Comprehensible input and second language acquisition: What is the relationship? Studies in Second Language Acquisition, 16, 303-324.

Macdonald, D. (1993, February). Learners and modified/negotiated interactions: What works for pronunciation. Paper presented at Second Language Acquisition-Foreign Language Learning III conference, Purdue University, West Lafayette, IN.

Nagle, S., \& Sanders, S. (1986). Comprehension theory and second language pedagogy. TESOL Quarterly, 20, 9-26.

Osborne, R. J., \& Wittrock, M. C. (1983). Learning science: A generative process. Science Education, 67, 489508.

Parker, K., \& Chaudron, C. (1987). The effects of linguistic simplifications and elaborative modifications on L.2 comprehension. University of Hawaii Working Papers in English as a Second Language, 6, 107-133.

Pica, T. (1987). Second-language acquisition, social interaction, and the classroom. Applied Linguistics, 8, 321.

Pica, T, \& Doughty, C. (1985). Input and interaction in the communicative classroom: A comparison of teacher-fronted and group activities. In S. Gass \& C. Madden (Eds.), Input in Second Language Acquisition (pp. 115-132). Rowley, MA: Newbury House.

Pica, T., Holliday, L., Lewis, N., Berducci, D., \& Newman, J. (1991). Language learning through interaction: What role does gender play? Studies in Second Language Acquisition, 13, 343-376.

Pica, T., Young, R., \& Doughty, C. (1987). The impact of interaction on comprehension. TESOL Quarterly, 21, 737-758.

Pienemann, M. (1992). Teachability theory. Unpublished manuscript, Sydney, Australia.

Plough, I., \& Gass, S. (1993). Interlocutor and task familiarity: Effects on interactional structure. In G. Crookes \& S. Gass (Eds.), Tasks and language learning: Integrating theory and practice (pp. 35-56). Clevedon, UK: Multilingual Matters.

Ross, S., Long, M., \& Yano, Y. (1992, July). Simplification or elaboration? The effects of two types of text modifications on foreign language reading comprehension. Paper presented at the Pacific Second Language Research Forum, University of Sydney, Australia.

Samuda, V., \& Rounds, P. (1993). Critical episodes: Reference points for analyzing a task in action. In G. Crookes \& S. Gass (Eds.), Tasks from a pedagogical perspective: Integrating theory and practice (pp. 125-138). Clevedon, UK: Multilingual Matters.

Sato, C. (1986). Conversation and interlanguage development: Rethinking the connection. In R. Day (Ed.), 
Talking to learn: Conversation in second language acquisition (pp. 23-45). Cambridge, MA: Newbury House.

Scarcella, R. (1983). Discourse accent in second language performance. In S. Gass \& L. Selinker (Eds.), Language transfer in language learning (pp. 306-326). Rowley, MA: Newbury House.

Scarcella, R. (1992). Interethnic conversation and second language acquisition: Discourse accent revisited. In S. Gass \& L. Selinker (Eds.), Language transfer in language learning (pp. 109-137). Amsterdam: John Benjamins.

Scarcella, R., \& Higa, C. (1981). Input, negotiation and age differences in second language acquisition. Language Learning, 31, 409-438.

Schachter, J. (1986). Three approaches to the study of input. Language Learning, 36, 211-225.

Schmidt, R. (1990). The role of consciousness in second language learning. Applied Linguistics, 11, 129-158.

Sharwood Smith, M. (1991). Speaking to many minds: On the relevance of different types of language information for the L2 learner. Second Language Research, 7, 118-132.

Tomlin, R., \& Villa, V. (1994). Attention in cognitive science and second language acquisition. Studies in Second Language Acquisition, 16, 183-203.

Varonis, E., \& Gass, S. (1985). Non-native/non-native conversations: A model for negotiation of meaning. Applied Linguistics, 6, 71-90.

Wagner-Gough, K., \& Hatch, E. (1975). The importance of input in second language acquisition studies. Language Learning, 25, 297-308.

White, L. (1987). Against comprehensible input: The input hypothesis and the development of secondlanguage competence. Applied Linguistics, 8, 95-100.

Woken, M., \& Swales, J. (1989). Expertise and authority in native-non-native conversations: The need for a variable account. In S. Gass, C. Madden, D. Preston, \& L. Selinker (Eds.), Variation in second language acquisition: Discourse and pragmatics (pp. 211-227). Clevedon, UK: Multilingual Matters.

Zuengler, J. (1989). Performance variation in NS-NNS interactions: Ethnolinguistic difference or discourse domain? In S. Gass, C. Madden, D. Preston, \& L. Selinker (Eds.), Variation in second language acquisition: Discourse and pragmatics (pp. 228-244). Clevedon, UK: Multilingual Matters. 